Bibliotech : Jurnal Ilmu Perpustakaan dan Informasi, 3 (2) 2018

\title{
EVALUASI PEMANFAATAN SISTEM INFORMASI KASUS \\ DENGAN MODEL INFORMATION SYSTEM SUCCESS DELONE \& \\ MCLEAN DI LEMBAGA BANTUAN HUKUM JAKARTA
}

\author{
Arif Syamsudin Budi Wahyudi ${ }^{1}$; Wardiyono ${ }^{2}$ \\ ${ }^{1}$ PT Boer Technology (Btech), Bogor \\ ${ }^{2}$ Program Studi S1 Ilmu Perpustakaan, Fakultas Teknologi Informasi, Universitas YARSI \\ Jakarta, Indonesia
}

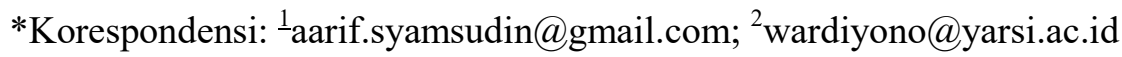

\begin{abstract}
ABSTRAK
Saat ini LBH Jakarta telah mengimplementasikan satu aplikasi yang memiliki peran penting dalam menangani pekerjaan-pekerjaan bantuan hukum. Model information system success Delone \& McLean digunakan untuk menganalisis Sistem Informasi Kasus (SIK) LBH. Terdapat enam variabel yang akan diuji dari yaitu, Information Quality, System Quality, Service Quality, Intention to Use/Use, User Satisfaction, dan Net Benefits. Hipotesis yang diajukan adalah, 1) Information Quality mempunyai pengaruh positif terhadap Intention to Use/Use; 2) System Quality mempunyai pengaruh positif terhadap Intention to Use/Use; 3) Service Quality mempunyai pengaruh positif terhadap Intention to Use/Use; 4) Information Quality mempunyai pengaruh postif terhadap User Satisfaction; 5) System Quality mempunyai pengaruh positif terhadap User Satisfaction; 6) Service Quality mempunyai pengaruh positif terhadap User Satisfaction; 7) Intention to Use/Use mempunyai pengaruh positif terhadap Net Benefits; 8) User Satisfaction mempunyai pengaruh positif terhadap Net Benefits. Hasil analisis deskriptif terhadap setiap pertanyaan yang ada di dalam variabel penelitian menunjukkan rerata nilai rendah - tinggi. Ditemukan juga dalam penelitian hal yang bertolak belakang dengan analisis data penelitian dengan menggunakan teknik analisis regresi linear berganda. Sebagian besar hipotesis yang ditawarkan pada penelitian ini ditolak. Namun, satu hipotesis yang diterima yaitu, Information Quality mempunyai pengaruh positif terhadap User Satisfaction. Melihat jumlah hipotesis yang ditolak, pemanfaatan SIK tidak memiliki nilai yang signifikan bagi LBH Jakarta. Hasil wawancara mendukung pembuktian hipotesis tersebut.
\end{abstract}

Kata kunci: Evaluasi, Model Information System Success, DeLone \& McLean, LBH Jakarta, Sistem Informasi Kasus

\section{PENDAHULUAN}

Otomatisasi merupakan satu bagian kecil dari keseluruhan sistem informasi yang dibangun untuk memudahkan pekerjaan manusia. Di dalam suatu organisasi yang modern, sistem informasi dibangun secara terintegrasi untuk memudahkan kerja-kerja rutin yang dilakukan oleh organisasi yang bersangkutan. Pendit (2008) menuliskan bahwa saat ini, sistem informasi sebagai teknologi sudah menjadi bagian yang tidak terpisahkan dari semua organisasi modern. Lanjut Pendit, penggunaan teknologi ini kemudian secara khusus memerlukan pengaturan dan pengelolaan yang bersifat khusus, sehingga sistem informasi itu sendiri akhirnya lebih sering disebut sebagai "manajemen sistem informasi" (information system management). 
Bibliotech : Jurnal Ilmu Perpustakaan dan Informasi, 3 (2) 2018

Lembaga Bantuan Hukum Jakarta (LBH Jakarta) merupakan salah satu lembaga yang proaktif dalam pemanfaatan teknologi serta sistem informasi. Dengan kerja-kerja advokasi bantuan hukum yang dilakukan oleh LBH Jakarta, internet menjadi salah satu media komunikasi yang efektif dalam menyampaikan informasi serta data-data yang diperlukan terkait kerja-kerja yang dilakukan oleh LBH Jakarta. Pemanfaatan sistem informasi sebagai alat bantu dalam mengelola kerja-kerja yang dilakukan oleh Pekerja Bantuan Hukum (PBH) pun mendapatkan perhatian signifikan.

Terkait pemanfaatan sistem informasi, saat ini LBH Jakarta telah mengimplementasikan beberapa sistem informasi yang secara keseharian digunakan dalam mengelola informasi. Satu aplikasi yang memiliki peran penting dalam menangani pekerjaan-pekerjaan bantuan hukum dinamakan Sistem Informasi Kasus. Setelah berjalan selama beberapa tahun, SIK LBH Jakarta sebagai suatu sistem informasi, belum pernah dilakukan pengukuran manfaatnya. Berdasarkan kenyataan tersebut, pada tahun 2015, LBH Jakarta memulai penelitian terkait sistem informasi yang ada. Tujuan dari penelitian tersebut adalah:

1. Besarnya biaya pembuatan sistem informasi, apakah telah sebanding dengan pemanfaatan dan hasil yang diperoleh;

2. Kehilangan data akan merugikan organisasi LBH Jakarta karena tidak menyimpan bukti yang menjadi memori kolektif lembaga, sehingga menyebabkan informasi tidak tertransfer dengan baik;

3. Informasi menjadi salah satu bahan untuk pengambilan keputusan organisasi;

4. Potensi kerugian jika terjadi kesalahan atau penyalahgunaan komputer;

5. Biaya pemeliharaan hardware dan software yang tinggi;

6. Biaya yang tinggi apabila komputer errors;

7. Perlunya security data khususnya data kasus (Tim Evaluasi Sistem Informasi, 2015).

Dari temuan-temuan yang dipaparkan tersebut, lantas didapat kesimpulan bahwa:

1. Perencanaan dan pengorganisasian yang masih kurang baik, karena tidak ada staf khusus IT yang memahami tentang teknologi informasi, penanganan kerusakan, dan pemeliharaan sehingga beberapa proses pengembangan dan perawatan menjadi kurang memadai;

2. Kesadaran pentingnya teknologi informasi sudah menjadi modal dasar dalam menentukan arah dalam proses bisnis organisasi, namun belum diikuti oleh realisasi penggunaan sistem dengan aktif;

3. Acquire dan implement di LBH Jakarta sudah cukup baik. Sistem dikembangkan menggunakan teknologi berbasis kode sumber terbuka sehingga memungkinkan untuk dimodifikasi dan pengembangan lebih lanjut untuk memberikan solusi terbaik demi mencapai tujuan. Dari sisi pengguna, sistem yang ada cukup user friendly. Namun dalam pengimplementasiannya masih belum maksimal, khususnya disiplin dan taat pada peraturan penggunaan; 
Bibliotech : Jurnal Ilmu Perpustakaan dan Informasi, 3 (2) 2018

4. Deliver dan support masih kurang maksimal karena keamanan sistem belum terjamin. Hal ini membuka peluang data dapat diakses, dimodifikasi, dan diambil oleh pihak yang tidak bertanggungjawab;

5. Belum adanya fasilitas pendukung yang dibutuhkan, seperti warning system untuk mempermudah kontrol;

6. Support system masih kurang maksimal dalam penyampaian, penyerahan, pengumpulan data atau dokumen, sehingga pengguna mengalami kesulitan dalam penyimpanan data;

7. Fasilitas server storage setiap tahun akan mengalami perkembangan kebutuhan penyimpanan, hal ini harus menjadi perhatian organisasi berkaitan dengan biaya;

8. Tidak ada rekaman pencatatan pada masalah-masalah yang ditimbulkan sistem, membuat sulit untuk mendeteksi dan memproteksi kesalahan atau penyalahgunaan sistem;

9. Monitor dan evaluate masih kurang baik karena tidak adanya penetapan target mengenai kemajuan kinerja TI itu sendiri;

10. Kewenangan dalam pemantauan sistem dan pemanfaatannya harus ditetapkan agar evaluasi selanjutnya mudah dilakukan (Tim Evaluasi Sistem Informasi 2015, Hal. 5-6).

Terkait kualitas data yang dimasukkan ke dalam SIK LBH Jakarta juga menjadi perhatian bagi peneliti untuk menakar apakah SIK LBH Jakarta memang benar-benar memberikan manfaat yang signifikan bagi LBH Jakarta dalam hal nilai tambah yang diberikan bagi kegiatan bantuan hukum. Memperhatikan latar belakang yang dijelaskan dalam paragraf sebelumnya, perumusan masalah yang akan dibuat dalam penelitian ini adalah:

1. Sejauh mana tingkat pemanfaatan SIK LBH Jakarta;

2. Faktor-faktor apa saja yang mempengaruhi tingkat pemanfaatan SIK LBH Jakarta;

3. Bagaimana kualitas data yang dihasilkan oleh aplikasi menurut pengguna SIK LBH Jakarta.

Penelitian ini dilakukan di LBH Jakarta dengan melibatkan PBH yang berada di lingkungan LBH Jakarta selama periode Juni - Juli 2017

\section{METODE}

Pada penelitian ini, metode penelitian yang akan digunakan adalah metode penelitian kuantitatif. Penelitian menggunakan metodologi evaluasi sistem informasi Delone dan McLean untuk melihat sejauh mana tingkat pemanfaatan serta faktor-faktor yang mempengaruhinya di LBH Jakarta. Jumlah populasi yang ada di LBH Jakarta adalah 43 (empat puluh tiga) PBH dengan komposisi Staf Umum, Pengacara Publik, serta Asisten Bantuan Hukum (ABH) yang melakukan kerja-kerja operasional di LBH Jakarta untuk diambil datanya terkait tujuan dari penelitian ini. 
Bibliotech : Jurnal Ilmu Perpustakaan dan Informasi, 3 (2) 2018

Menurut Sugiyono (2016, hlm. 62), sampel adalah bagian dari jumlah dan karakteristik yang dimiliki oleh populasi tersebut. Bila populasi besar dan peneliti tidak mungkin mempelajari semua yang ada pada populasi misalnya, karena keterbatasan dana, tenaga, dan waktu, maka peneliti dapat menggunakan sampel, diambil dari populasi itu. Apa yang dipelajari dari sampel itu, kesimpulannya akan dapat diberlakukan untuk populasi. Untuk itu, sampel yang diambil dari populasi harus betul-betul representatif (mewakili).

Atas dasar hal tersebut, maka pengambilan sampel dilakukan dengan menggunakan metode nonprobability sampling. Namun melihat kondisi di lapangan, pemilihan sampling yang diambil adalah sampling kuota karena sampai batas waktu yang ditentukan, jumlah data yang berhasil dikumpulkan hanya 90\% dari jumlah populasi, yaitu 39 (tiga puluh sembilan) orang. Penentuan ini diputuskan secara cepat agar data yang sudah masuk bisa segera diolah.

Dengan menggunakan metode evaluasi Information Success Models dari Delone dan McLean yang telah diperbarui, maka akan ada 6 (enam) variabel yang digunakan untuk menilai pemanfaatan sistem informasi yang ada di LBH Jakarta:

1. Kualitas sistem (system quality);

2. Kualitas informasi (information quality);

3. Kualitas layanan (service quality);

4. Niat untuk penggunaan (intention to use/use);

5. Kepuasan pengguna (user satisfaction);

6. Hasil akhir yang didapat (net benefits).

Berdasarkan teori Delone dan McLean yang diperbarui, yang digunakan sebagai dasar metodologi penelitian ini, maka kerangka pemikiran yang digunakan adalah:

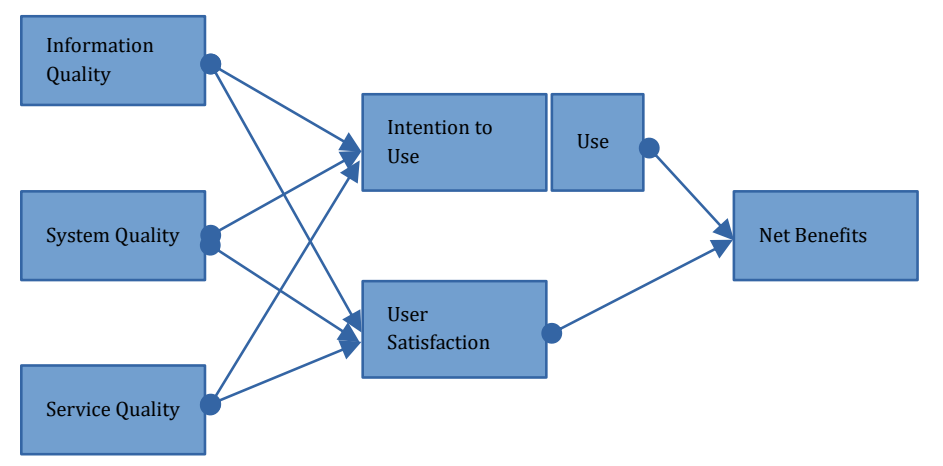

Gambar 1 Model Kesuksesan Sistem Informasi DeLone \& McLean

Menggunakan model pada Gambar 1 yang ditampilkan oleh Delone dan McLean, hipotesa yang penulis simpulkan berdasarkan kerangka pemikiran di atas adalah:

1. Information Quality mempunyai pengaruh positif terhadap Intention to Use/Use; 
Bibliotech : Jurnal Ilmu Perpustakaan dan Informasi, 3 (2) 2018

2. System Quality mempunyai pengaruh positif terhadap Intention to Use/Use;

3. Service Quality mempunyai pengaruh positif terhadap Intention to Use;

4. Information Quality mempunyai pengaruh postif terhadap User Satisfaction;

5. System Quality mempunyai pengaruh positif terhadap User Satisfaction;

6. Service Quality mempunyai pengaruh positif terhadap User Satisfaction;

7. Intention to Use/Use mempunyai pengaruh positif terhadap Net Benefits;

8. User Satisfaction mempunyai pengaruh positif terhadap Net Benefits;

Berdasarkan metode pengambilan sampel yang telah ditentukan, cara pengumpulan data yang akan dilakukan dengan memberikan angket (kuisioner). Jawaban kuisioner dibuat dengan menggunakan Skala Likert. Sugiyono (2012) menuliskan dengan Skala Likert, maka variabel yang akan diukur dijabarkan menjadi indikator variabel. Kemudian indikator tersebut dijadikan titik tolak untuk menyusun item-item instrumen yang dapat berupa pernyataan atau pertanyaan. Kuisioner menggunakan Skala Likert antara 1-4 dengan representasi (1) sangat tidak setuju, (2) tidak setuju, (3) setuju, dan (4) sangat setuju.

Pada penelitian ini, Analisis Regresi Berganda akan digunakan untuk mengolah data yang telah dikumpulkan. Analisa Regresi Berganda dipilih karena jumlah variabel independen yang digunakan dalam penelitian ini berjumlah lebih dari satu. Seperti dapat dilihat pada hipotesis yang ditawarkan.

Analisis Regresi diantaranya dapat dibedakan dengan Analisis Regresi Sederhana dan Analisis Regresi Berganda. Suliyatno (2011, hlm. 53) menjelaskan, perbedaan antara Regresi Sederhana dan Regresi Berganda terletak pada jumlah variabel bebasnya. Jika dalam Regresi Sederhana jumlah variabel bebas yang digunakan untuk memprediksi variabel tergantung hanya satu, maka dalam Regresi Berganda jumlah variabel bebas yang digunakan untuk memprediksi variabel tergantung, lebih dari satu.

Pada penelitian ini, terdapat beberapa variabel independen dan variabel dependen. Untuk analisa pertama, variabel independennya, (1) Information Quality, (2) System Quality, dan (3) Service Quality. Sedangkan variabel dependennya Intention to Use/Use. Untuk analisa kedua, variabel independennya adalah (1) Information Quality, (2) System Quality, dan (3) Service Quality, dengan variabel dependennya User Satisfaction. Terakhir, untuk analisa yang ketiga, variabel indepennya adalah (1) Intention to Use/Use dan (2) User Satisfaction, dengan variabel dependennya Net Benefits.

Dalam penelitian ini, juga dilakukan metode pengambilan data melalui wawancara. Metode ini diambil untuk melengkapi hasil analisa data. Pedoman wawancara yang digunakan oleh peneliti untuk mendapatkan informasi tambahan adalah wawancara tidak 
Bibliotech : Jurnal Ilmu Perpustakaan dan Informasi, 3 (2) 2018

terstruktur, karena harapannya dapat menjadi data tambahan untuk mendukung hasil pengolahan data. Sumber informasi wawancara digali dari Kepala Bidang Pusat Dokumentasi Bantuan Hukum (PDBH) LBH Jakarta yang secara langsung bertanggung jawab terhadap teknis operasional SIK serta analisa data SIK.

Tahapan penelitian yang digunakan pada penelitian ini dapat dilihat pada flowchart berikut:

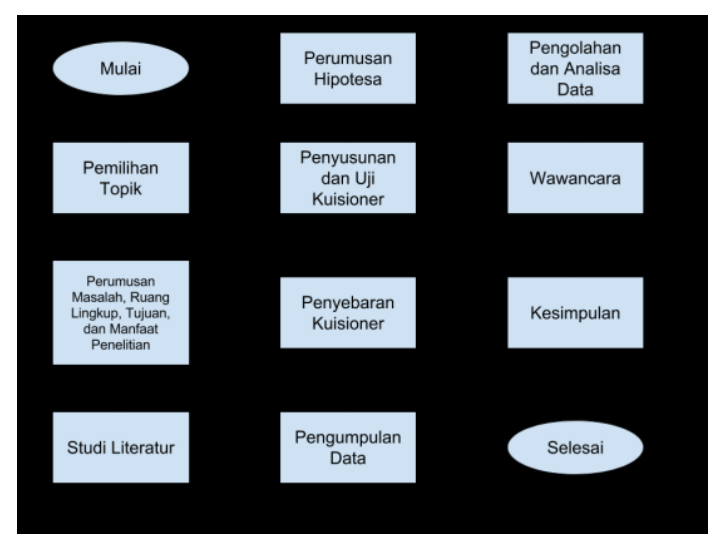

Gambar 2 Bagan Alur Tahapan Penelitian

\section{HASIL DAN PEMBAHASAN}

\subsection{Uji Kuisioner}

Uji kuisioner dilakukan untuk melihat seberapa valid pertanyaan- pertanyaan yang diajukan dalam suatu rangkaian kuisioner. Dengan melakukan pengujian, diharapkan jawaban yang diberikan mampu memberikan hasil yang solid, sehingga mampu menjawab maksud dan tujuan penelitian yang dilakukan.

Pada penelitian kali ini, uji validasi dilakukan kepada kurang lebih 20 (dua puluh) calon responden untuk diambil datanya. Dari 20 (dua puluh) calon responden, selama dua hari pengumpulan jawaban, terkumpul sebanyak 11 (sebelas) responden. Uji validasi dilakukan secara manual dengan menggunakan lembar-sebar (spreadsheet). Juliandi (2007) menyatakan, suatu item instrumen valid jika nilai korelasinya adalah "positif" dan "lebih besar atau sama dengan $r$ tabel”.

Berdasarkan hasil uji validitas yang dilakukan sebanyak tiga kali, berhasil dikumpulkan pertanyaan-pertanyaan kuisioner yang memiliki nilai valid, dimana nilai korelasi lebih besar daripada nilai rtable $=0,602$, di mana pada tiap pengujian, pertanyaan dalam kuisioner yang dinyatakan tidak valid, dihapus dari daftar pertanyaan, sampai terkumpul semua pernyataan yang memiliki nilai valid.

\subsection{Analisis Data}


Bibliotech : Jurnal Ilmu Perpustakaan dan Informasi, 3 (2) 2018

Pertanyaan yang disajikan pada kuisioner, dimasukkan ke dalam 6 (enam) variabel yang digunakan dalam penelitian. eenam variabel tersebut adalah:

1. Information Quality;

2. System Quality;

3. Service Quality;

4. Intention to Use/Use

5. User Benefits;

6. Net Benefits.

Analisis deskriptif pada penelitian ini adalah untuk menggambarkan karakteristik responden sesuai dengan variabel penelitian yaitu Information Quality, System Quality, Service Quality, Intention to Use/Use, User Satisfaction, dan Net Benefit, dalam memanfaatkan Sistem Informasi Kasus (SIK). Penilaian variabel penelitian dilakukan dengan Skala Likert 1=Sangat Tidak Setuju sampai 4=Sangat Setuju. Nilai rata-rata penelitian responden akan dikelompokkan ke dalam kelas interval sebesar 0,75 dengan pengelompokkan sebagai berikut:

$$
\begin{aligned}
& 1,00-1,74=\text { Sangat Rendah } \\
& 1,75-2,49=\text { Rendah } \\
& 2,50-3,24=\text { Tinggi } \\
& 3,25-4,00=\text { Sangat Tinggi }
\end{aligned}
$$

\section{Analisis Deskriptif Variabel Information Quality}

Berdasarkan nilai rata-rata di atas, diketahui bahwa nilai rata-rata terendah dari semua pertanyaan dalam variabel ini adalah 2,38 sedangkan nilai rata-rata terbesar adalah 2,85. Nilai rata-rata terendah masuk ke dalam kelompok kelas interval 1,75 - 2,49 dengan kategori rendah dan nilai rata-rata terbesar masuk ke dalam kelompok kelas interval 2,50 3,24 dengan kategori tinggi. Hal tersebut menunjukkan bahwa kualitas informasi yang dimasukkan dan dihasilkan oleh SIK adalah rendah - tinggi.

\section{Analisis Deskriptif Variabel System Quality}

Berdasarkan nilai rata-rata di atas, diketahui bahwa nilai rata-rata terendah dari semua pertanyaan dalam variabel ini adalah 2,62 sedangkan nilai rata-rata terbesar adalah 2,90. Nilai rata-rata terendah dan nilai rata-rata terbesar masuk ke dalam kelompok kelas interval 2,50 - 3,24 dengan kategori tinggi. Hal tersebut menunjukkan bahwa kualitas SIK sebagai sistem adalah tinggi.

\section{Analisis Deskriptif Variabel Service Quality}


Bibliotech : Jurnal Ilmu Perpustakaan dan Informasi, 3 (2) 2018

Berdasarkan nilai rata-rata di atas, diketahui bahwa nilai rata-rata terendah dari semua pertanyaan dalam variabel ini adalah 2,46 sedangkan nilai rata-rata terbesar adalah 2,92. Nilai rata-rata terendah masuk ke dalam kelompok kelas interval 1,75 - 2,49 dengan kategori rendah dan nilai rata-rata terbesar masuk ke dalam kelompok kelas interval 2,50 3,24 dengan kategori tinggi. Hal tersebut menunjukkan bahwa kualitas layanan yang diberikan adalah rendah - tinggi.

\section{Analisis Deskriptif Variabel Intention to Use/Use}

Berdasarkan nilai rata-rata di atas, diketahui bahwa nilai rata-rata terendah dari semua pertanyaan dalam variabel ini adalah 2,79 sedangkan nilai rata-rata terbesar adalah 2,97. Nilai rata-rata terendah dan nilai rata-rata terbesar masuk ke dalam kelompok kelas interval 2,50 - 3,24 dengan kategori tinggi. Hal tersebut menunjukkan bahwa penggunaan SIK untuk menyelesaikan pekerjaan adalah tinggi.

\section{Analisis Deskriptif Variabel User Satisfaction}

Berdasarkan nilai rata-rata di atas, diketahui bahwa nilai rata-rata terendah dari semua pertanyaan dalam variabel ini adalah 2,87 sedangkan nilai rata-rata terbesar adalah 2,97. Nilai rata-rata terendah dan nilai rata-rata terbesar masuk ke dalam kelompok kelas interval 2,50 - 3,24 dengan kategori tinggi. Hal tersebut menunjukkan bahwa kepuasan pengguna dalam memaanfaatkan SIK adalah tinggi.

\section{Analisis Deskriptif Variabel Net Benefits}

Berdasarkan nilai rata-rata di atas, diketahui bahwa nilai rata-rata terendah dari semua pertanyaan dalam variabel ini adalah 2,85 sedangkan nilai rata-rata terbesar adalah 3,00. Nilai rata-rata terendah dan nilai rata-rata terbesar masuk ke dalam kelompok kelas interval 2,50 - 3,24 dengan kategori tinggi. Hal tersebut menunjukkan bahwa keuntungan pemanfaatan SIK sebagai suatu sistem adalah tinggi.

Hasil analisis deskriptif terhadap setiap pertanyaan yang ada di dalam variabel penelitian menunjukkan rerata nilai rendah - tinggi, begitu pula dengan hasil bacaan terhadap persentase jawaban yang diberikan oleh responden untuk tiap pertanyaan di dalam variabel. Namun demikian, terdapat hal yang bertolak belakang dengan analisis data penelitian dengan menggunakan teknik analisis regresi linear berganda.

Proses penghitungan akan dibagi menjadi tiga bagian, karena masing-masing variabel dihitung sesuai dengan proses penghitungan pada Analisis Regresi Berganda. Teknik penghitungan yang digunakan adalah Uji Tabel t (parsial) dan Probabilitas dengan menggunakan data dari tabel Model Summary dan Coefficients. 
Bibliotech : Jurnal Ilmu Perpustakaan dan Informasi, 3 (2) 2018

\section{Uji Kesatu}

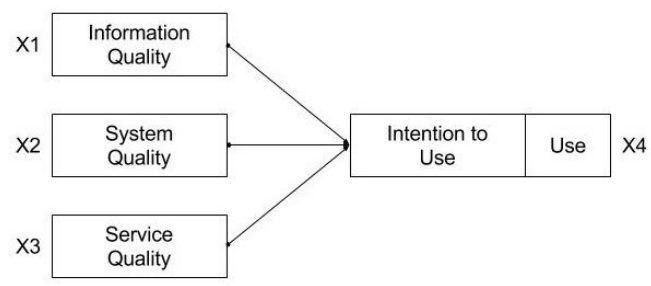

Gambar 3. Korelasi antar variabel Uji Kesatu

Model Summary

\begin{tabular}{|l|l|l|l|l|}
\hline Mode & $\mathrm{R}$ & R Square & Adjusted R Square & $\begin{array}{l}\text { Std. Error of the } \\
\text { Estimate }\end{array}$ \\
\hline 1 & $.353^{\mathrm{a}}$ & .124 & .049 & .73495 \\
\hline
\end{tabular}

a. Predictors: (Constant), Service Quality, System Quality, Information Quality ANOVA $^{\mathrm{a}}$

\begin{tabular}{|l|l|l|l|l|l|l|}
\hline \multicolumn{2}{|l|}{ Model } & Sum of Squares & df & Mean Square & F & Sig. \\
\hline \multirow{3}{*}{1} & Regression & 2.684 & 3 & .895 & 1.657 & $.194^{\mathrm{b}}$ \\
\cline { 2 - 7 } & Residual & 18.905 & 35 & .540 & & \\
\cline { 2 - 5 } & Total & 21.590 & 38 & & & \\
\hline
\end{tabular}

a. Dependent Variable: Intention to Use

b. Predictors: (Constant), Service Quality, System Quality, Information Quality Coefficients $^{\mathrm{a}}$

\begin{tabular}{|c|c|c|c|c|c|c|}
\hline \multirow{2}{*}{\multicolumn{2}{|c|}{ Model }} & \multicolumn{2}{|c|}{$\begin{array}{l}\text { Unstandardized } \\
\text { Coefficients }\end{array}$} & \multirow{2}{*}{\begin{tabular}{|l} 
Standardized \\
Coefficients \\
Beta
\end{tabular}} & \multirow[t]{2}{*}{$\mathrm{t}$} & \multirow[t]{2}{*}{ Sig. } \\
\hline & & $\mathrm{B}$ & Std. Error & & & \\
\hline \multirow{4}{*}{1} & (Constant) & 7.668 & 1.789 & & 4.286 & .000 \\
\hline & Information & .033 & .084 & .065 & 393 & .697 \\
\hline & System Quality & .159 & 147 & 179 & 1.081 & .287 \\
\hline & Service Quality & .157 & .098 & .257 & 1.600 & .119 \\
\hline
\end{tabular}

a. Dependent Variable: Intention to Use

Tabel 1. Hasil Analisis Regresi Linier Variabel Uji Kesatu

Pembuktian hipotesis pertama secara parsial dilakukan dengan membandingkan $\mathrm{t}_{\text {hitung }}$ dan $\mathrm{t}_{\text {tabel }}$ dari variabel Information Quality terhadap variabel Intention to Use/Use dengan hasil nilai $t_{\text {hitung }}=0,39 \leq \mathrm{t}_{\text {tabel }}=2,02619$ dan teknik probabilitas yang menghasilkan bahwa nilai Sig. $=0,697>\alpha=0,05$, yang hasilnya secara bersamaan menolak hipotesis yang diajukan. Dengan kata lain variabel Information Quality tidak memiliki pengaruh yang positif terhadap Intention to Use/Use dari aplikasi SIK.

Hasil ini, berdasarkan wawancara, bisa jadi karena dipengaruhi oleh kurang lengkapnya data yang dimasukkan oleh pengguna SIK. Dengan kurang lengkapnya data yang dimasukkan, niat pengguna untuk memanfaatkan aplikasi menjadi berkurang.

Pembuktian hipotesis kedua secara parsial dilakukan dengan membandingkan $t_{\text {hitung }}$ dan $t_{\text {tabel }}$ dari variabel System Quality terhadap variabel Intention to Use/Use dengan hasil nilai $t_{\text {hitung }}=1,081 \leq \mathrm{t}_{\text {tabel }}=2,02619$ dan teknik probabilitas yang menghasilkan bahwa nilai 
Bibliotech : Jurnal Ilmu Perpustakaan dan Informasi, 3 (2) 2018

Sig. $=0,287>\alpha=0,05$, yang hasilnya secara bersamaan menolak hipotesis yang diajukan. Dengan kata lain variabel System Quality tidak memiliki pengaruh yang positif terhadap Intention to Use/Use dari aplikasi SIK.

Kualitas sistem memang secara teknis memang masih perlu diperbaiki. Masih ada beberapa hal yang perlu diperbaiki dan ditambahkan dari sistem yang ada sekarang sehingga akan menambah nyaman penggunaan SIK.

Pembuktian hipotesis ketiga secara parsial dilakukan dengan membandingkan $t_{\text {hitung }}$ dan $\mathrm{t}_{\text {tabel }}$ dari variabel Service Quality terhadap variabel Intention to Use/Use dengan hasil nilai $\mathrm{t}_{\text {hitung }}=1,600 \leq \mathrm{t}_{\text {tabel }}=2,02619$ dan teknik probabilitas yang menghasilkan bahwa nilai Sig. $=0,119>\alpha=0,05$, yang hasilnya secara bersamaan menolak hipotesis yang diajukan. Dengan kata lain variabel Service Quality tidak memiliki pengaruh yang positif terhadap Intention to Use/Use dari aplikasi SIK.

Kualitas layanan terhadap penggunaan SIK juga menjadi satu kelemahan, menurut informan. Karena belum ada SOP mengenai bagaimana cara penanganan masalah penggunaan SIK. Kurangnya layanan terhadap penggunaan bisa menjadi satu alasan kenapa hipotesis ini ditolak.

\section{Uji Kedua}

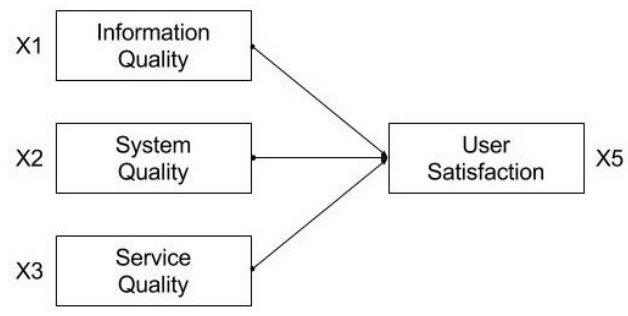

Gambar 4. Korelasi antar variabel Uji Kedua

Tabel 2. Hasil Analisis Regresi Linier Variabel Uji Kedua

Model Summary

\begin{tabular}{|l|l|l|l|l|}
\hline Model & R & R Square & Adjusted R Square & Std. Error of the Estimate \\
\hline 1 & $381^{\mathrm{a}}$ & 145 & .072 & .59117 \\
\hline
\end{tabular}

a. Predictors: (Constant), Service Quality, System Quality, Information Quality ANOVAa $^{a}$

\begin{tabular}{|l|l|l|l|l|l|l|}
\hline \multicolumn{2}{|l|}{ Model } & Sum of Squares & df & Mean Square & F & Sig. \\
\hline \multirow{3}{*}{1} & Regression & 2.076 & 3 & .692 & 1.980 & $.135^{\mathrm{b}}$ \\
& Residual & 12.232 & 35 & .349 & & \\
\cline { 2 - 7 } & Total & 14.308 & 38 & & & \\
\hline
\end{tabular}

a. Dependent Variable: User Satisfaction

b. Predictors: (Constant), Service Quality, System Quality, Information Quality 
Bibliotech : Jurnal Ilmu Perpustakaan dan Informasi, 3 (2) 2018

Coefficients $^{\mathrm{a}}$

\begin{tabular}{|c|c|c|c|c|c|c|}
\hline \multirow{2}{*}{\multicolumn{2}{|c|}{ Model }} & \multicolumn{2}{|c|}{ Unstandardized Coefficients } & \multirow{2}{*}{\begin{tabular}{|l} 
Standardized \\
Coefficients \\
Beta
\end{tabular}} & \multirow[t]{2}{*}{$T$} & \multirow[t]{2}{*}{ Sig. } \\
\hline & & B & Std Error & & & \\
\hline \multirow{4}{*}{1} & (Constant) & 9.524 & 1.439 & & 6.619 & .000 \\
\hline & Information Quality & 158 & .068 & 381 & 2.330 & 026 \\
\hline & System Quality & .020 & .118 & -.028 & -.171 & 866 \\
\hline & Service Quality & .018 & .079 & .036 & .229 & .820 \\
\hline
\end{tabular}

a. Dependent Variable: User Satisfaction

Pembuktian hipotesis keempat secara parsial dilakukan dengan membandingkan $\mathrm{t}_{\text {hitung }}$ dan $\mathrm{t}_{\text {tabel }}$ dari variabel Information Quality terhadap variabel User Satisfaction dengan hasil nilai $\mathrm{t}_{\text {hitung }}=2,330>\mathrm{t}_{\text {tabel }}=2,02619$ dan teknik probabilitas yang menghasilkan bahwa nilai Sig. $=0,026 \leq \alpha=0,05$, yang hasilnya secara bersamaan menerima hipotesis yang diajukan. Dengan kata lain variabel Information Quality memiliki pengaruh yang positif terhadap User Satisfaction dari aplikasi SIK. Penerimaan hipotesis ini dikarenakan para pengguna sudah merasa cukup mendapatkan informasi dari SIK.

Pembuktian hipotesis kelima secara parsial dilakukan dengan membandingkan $t_{\text {hitung }}$ dan $t_{\text {tabel }}$ dari variabel System Quality terhadap variabel User Satisfaction dengan hasil nilai $\mathrm{t}_{\text {hitung }}=-0,171 \leq \mathrm{t}_{\text {tabel }}=2,02619$ dan teknik probabilitas yang menghasilkan bahwa nilai Sig. $=0,866>\alpha=0,05$, yang hasilnya secara bersamaan menolak hipotesis yang diajukan. Dengan kata lain variabel System Quality tidak memiliki pengaruh yang positif terhadap User Satisfaction dari aplikasi SIK.

Nilai $t_{\text {hitung }}$ negatif menggambarkan bahwa apa yang diinginkan oleh pengguna terhadap SIK belum sepenuhnya sesuai dengan harapan para penggunanya.

Pembuktian hipotesis keenam secara parsial dilakukan dengan membandingkan $t_{\text {hitung }}$ dan $t_{\text {tabel }}$ dari variabel Service Quality terhadap variabel User Satisfaction dengan hasil nilai $\mathrm{t}_{\text {hitung }}=0,229 \leq \mathrm{t}_{\text {tabel }}=2,02619$ dan teknik probabilitas yang menghasilkan bahwa nilai Sig. $=0,820>\alpha=0,05$, yang hasilnya secara bersamaan menolak hipotesis yang diajukan. Dengan kata lain variabel Service Quality tidak memiliki pengaruh yang positif terhadap User Satisfaction dari aplikasi SIK.

Pengguna pun merasa bahwa tanggapan dari pengelola SIK terhadap keluhan-keluhan atas mereka kurang bisa ditanggapi. Hal ini sejalan dengan hasil wawancara yang menjelaskan bahwa kemampuan teknis dari pengelola sistem sangat kurang, ketika pengguna membutuhkan penambahan fitur dalam SIK. 
Bibliotech : Jurnal Ilmu Perpustakaan dan Informasi, 3 (2) 2018

Uji Ketiga

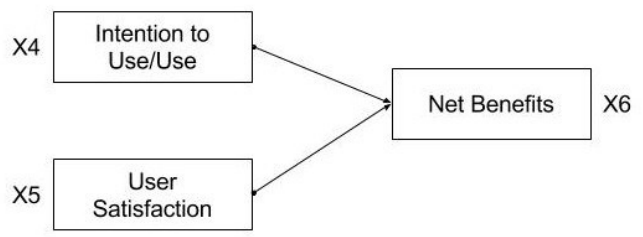

Gambar 5. Korelasi antar variabel Uji Ketiga

Tabel 3. Hasil Analisis Regresi Linier Variabel Uji Ketiga

Model Summary

\begin{tabular}{|l|l|l|l|l|}
\hline Model & R & R Square & Adjusted R Square & Std. Error of the Estimate \\
\hline 1 & $.281^{\mathrm{a}}$ & .079 & .028 & .76155 \\
\hline
\end{tabular}

a. Predictors: (Constant), User Satisfaction, Intention to Use

ANOVAa $^{a}$

\begin{tabular}{|l|l|l|l|l|l|l|}
\hline \multicolumn{2}{|l|}{ Model } & Sum of Squares & df & Mean Square & F & Sig. \\
\hline \multirow{3}{*}{1} & Regression & 1.788 & 2 & .894 & 1.541 & $228^{\mathrm{b}}$ \\
\cline { 2 - 7 } & Residual & 20.879 & 36 & .580 & & \\
\cline { 2 - 5 } & Total & 22.667 & 38 & & & \\
\hline
\end{tabular}

a. Dependent Variable: Net benefit

b. Predictors: (Constant), User Satisfaction, Intention to Use

Coefficientsa

\begin{tabular}{|c|c|c|c|c|c|c|}
\hline \multirow{2}{*}{\multicolumn{2}{|c|}{ Model }} & \multicolumn{2}{|c|}{ Unstandardized Coefficients } & \multirow{2}{*}{\begin{tabular}{|l} 
Standardized \\
Coefficients \\
Beta
\end{tabular}} & \multirow[t]{2}{*}{$t$} & \multirow[t]{2}{*}{ Sig. } \\
\hline & & $B$ & Std. Error & & & \\
\hline \multirow{3}{*}{1} & (Constant) & 8.055 & 2.962 & & 2.719 & .010 \\
\hline & Intention to Use & -.043 & .164 & .042 & -.265 & .793 \\
\hline & User Satisfaction & .352 & 202 & 280 & 1.746 & .089 \\
\hline
\end{tabular}

a. Dependent Variable: Net benefit

Pembuktian hipotesis ketujuh secara parsial dilakukan dengan membandingkan $\mathrm{t}_{\text {hitung }}$ dan $\mathrm{t}_{\text {tabel }}$ dari variabel Intention to Use/Use terhadap variabel Net Benefits dengan hasil nilai $t_{\text {hitung }}=-0,265 \leq \mathrm{t}_{\text {tabel }}=2,02619$ dan teknik probabilitas yang menghasilkan bahwa nilai Sig. $=0,793>\alpha=0,05$, yang hasilnya secara bersamaan menolak hipotesis yang diajukan. Dengan kata lain variabel Intention to Use/Use tidak memiliki pengaruh yang positif terhadap Net Benefits dari aplikasi SIK.

Bagi lembaga, ketika hipotesis ini tidak diterima, menjadi masalah tersendiri. Artinya, SIK dianggap tidak memiliki manfaat yang positif dalam mendukung kerja-kerja lembaga. Padahal, untuk beberapa hal, data keluaran SIK ini sudah dimanfaatkan untuk mendukung beberapa kerja-kerja penelitian.

Pembuktian hipotesis kedelapan secara parsial dilakukan dengan membandingkan $\mathrm{t}_{\text {hitung }}$ dan $\mathrm{t}_{\text {tabel }}$ dari variabel User Satisfaction terhadap variabel Net Benefits dengan hasil nilai thitung $=1,746 \leq \mathrm{t}$ tabel $=2,02619$ dan teknik probabilitas yang menghasilkan bahwa 
Bibliotech : Jurnal Ilmu Perpustakaan dan Informasi, 3 (2) 2018

nilai Sig. $=0,089>\alpha=0,05$, yang hasilnya secara bersamaan menolak hipotesis yang diajukan. Dengan kata lain variabel User Satisfaction tidak memiliki pengaruh yang positif terhadap Net Benefits dari aplikasi SIK.

Sama seperti hipotesis sebelumnya, bahwa dengan ditolaknya ini, pengguna merasa bahwa SIK tidak cukup baik bagi mereka, untuk membantu kerja-kerja yang dilakukan oleh pengguna.

Tabel 4 merangkum pernyataan-pernyataan hasil pengujian hipotesis.

Tabel 4. Hasil Pengujian Hipotesis

\begin{tabular}{|c|l|l|}
\hline No. & Hipotesis & Hasil Penelitian \\
\hline 1 & $\begin{array}{l}\text { Information Quality mempunyai pengaruh positif terhadap } \\
\text { Intention to Use/Use }\end{array}$ & Hipotesis ditolak \\
\hline 2 & $\begin{array}{l}\text { System Quality mempunyai pengaruh positif terhadap } \\
\text { Intention to Use/Use }\end{array}$ & Hipotesis ditolak \\
\hline 3 & $\begin{array}{l}\text { Service Quality mempunyai pengaruh positif terhadap } \\
\text { Intention to Use/Use }\end{array}$ & Hipotesis ditolak \\
\hline 4 & $\begin{array}{l}\text { Information Quality mempunyai pengaruh positif terhadap } \\
\text { User Satisfaction }\end{array}$ & Hipotesis diterima \\
\hline 5 & $\begin{array}{l}\text { System Quality mempunyai pengaruh positif terhadap User } \\
\text { Satisfaction }\end{array}$ & Hipotesis ditolak \\
\hline 6 & $\begin{array}{l}\text { Service Quality mempunyai pengaruh positif terhadap User } \\
\text { Satisfaction }\end{array}$ & Hipotesis ditolak \\
\hline 7 & $\begin{array}{l}\text { Intention to Use/Use mempunyai pengaruh positif terhadap } \\
\text { Net Benefits }\end{array}$ & Hipotesis ditolak \\
\hline 8 & $\begin{array}{l}\text { User Satisfaction mempunyai pengaruh positif terhadap Net } \\
\text { Benefits }\end{array}$ & Hipotesis ditolak \\
\hline
\end{tabular}

\subsection{Hasil Wawancara}

Dari hasil wawancara, peneliti memaparkan hasil uji hipotesis yang menurut informan, bahwa ada beberapa hal yang bisa menjadi faktor kenapa muncul hasil uji hipotesis seperti itu:

\section{Perubahan Kebiasaan}

Perubahan kebiasaan dari budaya cetak ke budaya dijital. SIK baru diimplementasikan secara penuh pada pertengahan than 2014. Sebelumnya, catatan penanganan kasus dicatat secara manual baik itu melalui media formulir tercetak maupun ke dalam aplikasi komputer seperti pengolah kata. Akibatnya, dengan diterapkannya SIK, banyak $\mathrm{PBH}$ yang belum siap secara kebiasaan dalam mengelola pekerjaannya.

2. Tingkat regenerasi Pekerja Bantuan Hukum $(\mathrm{PBH})$ yang tinggi 
Bibliotech : Jurnal Ilmu Perpustakaan dan Informasi, 3 (2) 2018

Sebagai lembaga yang progresif, setiap tahunnya LBH Jakarta selalu mencari bakat-bakat baru untuk bisa bergabung dalam lingkungan pekerjaan LBH Jakarta. Setiap tahunnya, untuk keperluan penanganan kasus saja, selalu ada pergantian Asisten Bantuan Hukum (ABH). Jumlahnya cukup signifikan, kurang lebih sekitar $35 \%$ dari total PBH yang ada di LBH Jakarta. Karena turnover tersebut, ketika seseorang pekerja sudah mulai nyaman dengan pola kerja yang ada, namun harus diganti. Kemudian usaha yang besar kembali diperlukan untuk mendidik PBH yang baru agar bisa memahami sistem yang sudah berjalan.

3. Akses yang terbatas

Saat ini, SIK hanya bisa diakses melalui jaringan komputer kantor LBH Jakarta. Ketika ada kebutuhan akses dari luar kantor, masih belum bisa dilakukan dengan alasan keamanan data.

4. Pemasukan data yang kurang lengkap

Berdasarkan informasi yang diberikan informan, masih terjadi, dan amat sering, kebiasaan pengguna SIK untuk tidak memasukkan data penanganan kasus secara lengkap. Hal ini tersebut menjadi hambatan tersendiri dalam hal pengolahan data agar hasilnya dapat digunakan untuk hal lain, data pendukung untuk penulisan hasil penelitian, misalnya.

5. Prosedur pengembangan aplikasi yang kurang ramah

Dalam proses pengembangan aplikasi diakui bahwa pada akhirnya, harus diatur agar tidak semua memberikan masukkan. Karena jika semua pihak yang berkepentingan dalam memanfaatkan SIK ini nanti dilibatkan, maka proses pengembangan akan terhambat karena semakin banyak yang terlibat, semakin banyak masukan, dan semakin membuat bingung pengembang aplikasi, karena ini terkait dengan adanya target penyelesaian sistem yang pendek.

6. Kurangnya kemampuan teknis pengelola SIK

Hal ini menjadi tantangan tersendiri ketika pengelola mendapatkan masukkan untuk melakukan penambahan fitur yang berkaitan dengan aktivitas penggunaan SIK. Untuk hal ini, mereka sangat tergantung bantuan dari pihak luar sementara dana pengembangan tidak selalu tersedia.

7. Tidak adanya dukungan yang pasti dari level manajemen

Tidak ada sanksi yang jelas ketika seorang PBH tidak memasukkan data secara lengkap, padahal secara tidak langsung, ketidaklengkapan itu akan menyulitkan proses pengolahan data, rekapitulasi data. Ketika sudah ada aturan main yang ditetapkan sekalipun, aturan main tersebut hanya sekedar ada. Dilihat jika 
Bibliotech : Jurnal Ilmu Perpustakaan dan Informasi, 3 (2) 2018

diperlukan. Penegakkan pasal-pasal kesepakatan dalam aturan main tersebut tidak terlalu nyata dan hanya bersifat parsial.

\section{KESIMPULAN}

A. Sejauh mana tingkat pemanfaatan SIK di LBH Jakarta

Tingkat pemanfaatan SIK di LBH Jakarta diwakili oleh variabel Intention to Use/Use. Walaupun dilihat dari koefisien determinasi, variabel ini hanya mendapatkan pengaruh sebesar $12,4 \%$, namun dilihat dari analisis deskriptif variabel ini, pada kelas interval 2,503,24, artinya tingkat pemanfaatan SIK dikatakan tinggi. Dari semua pertanyaan yang diajukan dalam variabel ini, skala setuju - sangat setuju menunjukkan persentase di atas 50\% (ItU1 - 84,6\%, ItU2 - 94,8\%, ItU3 - 97,5\%, ItU4 - 79,5\%).

Faktor-faktor apa saja yang mempengaruhi tingkat pemanfaatan SIK LBH Jakarta? Berdasarkan pertanyaan yang diberikan dalam tiap-tiap variabel serta presentase jawaban yang diberikan, maka faktor-faktor yang mempengaruhi tingkat pemanfaatan SIK LBH Jakarta adalah:

1. System Quality dengan hasil analisis deskriptif masuk ke dalam kategori tinggi;

2. User Satisfaction dengan hasil analisis deskriptif masuk ke dalam kategori tinggi;

3. Net benefits dengan hasil analisis deskriptif masuk ke dalam kategori tinggi;

4. Kemudian Service Quality dengan hasil analisis deskriptif masuk ke dalam kategori rendah - tinggi.

B. Bagaimana kualitas data yang dihasilkan oleh aplikasi menurut pengguna SIK LBH Jakarta

Rumusan ini dapat dijawab dengan melihat pada:

1. Hipotesis keempat yang menyatakan bahwa Information Quality mempunyai pengaruh positif terhadap User Satisfaction. Dengan kata lain, pengguna SIK merasakan bahwa data yang diberikan oleh sistem dapat menjawab kebutuhan mereka.

2. Analisis deskriptif berdasarkan variabel Information Quality. Walapun pada analisis ini, tingkat kategori yang disematkan adalah rendah - tinggi, namun dari semua pertanyaan yang diajukan, skala setuju - sangat setuju menunjukkan persentase di atas 50\% (IQ1 - 89,8\%, IQ2 - 87,2\%, IQ3 - 76,9\%, IQ4 - 56,5\%, IQ5 - 74,3\%). 
Bibliotech : Jurnal Ilmu Perpustakaan dan Informasi, 3 (2) 2018

3. Dari variabel Net Benefits, pada NB1 kita dapat melihat bahwa tingkat jawaban setuju - sangat setuju masing-masing memiliki nilai $82,1 \%$ dan $5,1 \%$ dan pada NB2, tingkat jawaban setuju - sangat setuju masing-masing memiliki nilai 76,9\% dan $23,1 \%$.

Sedangkan saran yang dapat diberikan dari hasil penelitian di atas:

a. Bagi peneliti yang akan melakukan penelitian menggunakan metode yang sama atau melanjutkan penelitian ini, perhatikan syarat-syarat dalam memulai suatu penelitian sehingga pada akhirnya mampu menyimpulkan dengan baik hasil penelitian berdasarkan analisis data yang valid.

b. Sekiranya LBH Jakarta sebagai pemanfaat SIK mampu memperhatikan hal-hal krusial seperti:

1. Mengantisipasi perubahan kebiasaan dari penggunaan media cetak ke dalam media dijital;

2. Mendokumentasikan berbagai hal dengan baik mengingat tingginya tingkat regenerasi PBH di LBH Jakarta;

3. Mempertimbangkan untuk menyediakan akses tak terbatas untuk pemanfaatan SIK;

4. Memperhatikan kelengkapan-kelengkapan data yang dimasukkan ke dalam SIK;

5. Melibatkan pengguna SIK secara aktif untuk pengembangan SIK selanjutnya;

6. Meningkatkan kemampuan teknis pengelola SIK, utamanya untuk mengatasi hal-hal kecil pada SIK seperti menambahkan tabel pada pangkalan data untuk keperluan analisa sederhana atau memperbaiki galatgalat yang sifatnya tidak terlalu rumit;

7. Adanya dukungan yang jelas dari pihak manajemen terkait pemanfaatan SIK, misal dengan mengapresiasi pengguna SIK yang mampu mengisi data dengan baik dan lengkap atau memberikan peringatan bagi pengguna SIK yang tidak dengan segera melengkapi data. 
Bibliotech : Jurnal Ilmu Perpustakaan dan Informasi, 3 (2) 2018

\section{DAFTAR PUSTAKA}

DeLone, WH, McLean, ER (2003), 'The DeLone and McLean Model of Information System Success: A Ten-Year Update', Journal of Management Information Systems, Vol. 19, No. 4, Spring, p.9-30.

Juliandi, A (2007), Teknik Pengujian Validitas dan Reliabilitas, dilihat pada tanggal 10 Agustus 2017, https://goo.gl/d1dbXr

Pendit, PL (2008), Perpustakaan Digital dari A sampai Z, Cita Karyakarsa Mandiri, Jakarta

Sugiyono (2012), Metode Penelitian Kombinasi (Mixed Methods), Penerbit Alfabeta, Bandung

Sugiyono (2016), Statistika untuk Penelitian, Penerbit Alfabeta, Bandung

Suliyanto (2011), Ekonometrika Terapan: Teori dan Aplikasi dengan SPSS, Penerbit Andi, Yogyakarta

Tim Evaluasi Sistem Informasi (2015), 'Laporan Evaluasi Sistem Informasi LBH Jakarta (SILeBAH).' Laporan dibuat sebagai hasil akhir kegiatan evaluasi sistem informasi, LBH Jakarta, Jakarta 
Bibliotech : Jurnal Ilmu Perpustakaan dan Informasi, 3 (2) 2018 